\title{
First highlight of sound production in the glassy sweeper Pempheris schomburgkii (Pempheridae)
}

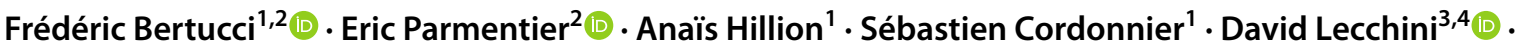 \\ Malika René-Trouillefou ${ }^{1,4}$ (1)
}

Received: 16 September 2020 / Accepted: 9 January 2021

(c) The Author(s), under exclusive licence to Springer-Verlag GmbH, DE part of Springer Nature 2021

\begin{abstract}
Many sounds produced by fishes remain to be described. Understanding sound production for vocal species would permit the development of passive acoustic monitoring of fish diversity. The present study investigated sound production in the glassy sweeper Pempheris schomburgkii in Guadeloupe reefs, French West Indies. Two recording approaches were used: passive acoustic monitoring in the wild and active recordings with hand-held individuals in captivity. Calls consisted of series of harmonic pop sounds with a dominant frequency of $360 \mathrm{~Hz}$. On coral reefs, they were produced in chorus, starting after sunset and lasting up to $3 \mathrm{~h}$. Sounds recorded in situ were longer with more pulses than sounds recorded from captive specimens. These differences in temporal features suggest two types of sounds: acoustic signals that act as distress calls and those that might be involved in group-level activities such as group cohesion and reproduction. A morphological study was also performed to describe the anatomy of the sound production apparatus which consisted of a pair of large sonic muscles which inserted dorsally on a contractible anterior part of the swim bladder. Contractions of these muscles extend rostrally this part of the swim bladder while an inner sheet of elastic connective tissue acts as a recoiling system to help the swim bladder recover its initial position during relaxation of the sonic muscles. The present results, therefore, contribute to the description of sound production by fishes found in an underexplored region and further illustrate how passive acoustics may be used to monitor fish populations in the future.
\end{abstract}

\section{Introduction}

More than 800 fish species from over 100 families have been documented to produce sounds (Ladich and Fine 2006; Bass and Ladich 2008), but this number is most probably an underestimate (Fine and Parmentier 2015). Contrarily to

Responsible Editor: D. Goulet.

Reviewed by M.T. Schärer and an undisclosed expert.

Frédéric Bertucci

fred.bertucci@gmail.com

1 Laboratoire de Biologie des Organismes et Ecosystèmes Aquatiques (BOREA), Université des Antilles, MNHN, SU, UCN, CNRS, IRD, Fouillole, 97157 Pointe-à-Pitre, Guadeloupe

2 Functional and Evolutionary Morphology Lab, University of Liège, Liège, Belgium

3 PSL Research University: EPHE-UPVD-CNRS, USR, 3278 CRIOBE Moorea, French Polynesia

4 Laboratoire d'Excellence "CORAIL", Perpignan, France
Jacques-Yves Cousteau's statement in 1956, the ocean has never been a silent world as acoustic cues can be involved in spatial orientation, intra- and inter-specific communication, predation, predator avoidance and navigating obstacles (Popper et al. 2001; Parmentier et al. 2015). Thus, the calling behaviour of marine animals, together with abiotic sounds, provide natural tags for the identification, tracking and estimation of stocks (Mann and Lobel 1995), as well as for the description of marine soundscapes (Bertucci et al. 2015). In recent years, a lot of progress has been made in the field of underwater acoustics, notably enhancing our understanding of the diversity of acoustic signals in marine and freshwater environments (Fine and Parmentier 2015; Ruppé et al. 2015) and the impact of anthropogenic sounds on fish populations (Vasconcelos et al. 2007; Slabbekoorn et al. 2010; Picciulin et al. 2012). Passive acoustic monitoring (PAM), i.e. the use of automatic audio recorders in the wild, can now help uncover both broad and fine-scale ecological patterns (Sueur and Farina 2015). Furthermore, it can provide information on ecosystem functioning by documenting the activities and dynamics of soniferous (i.e. sound-producing) species over 
a wide range of temporal and spatial scales (Rountree et al. 2006; Gannon 2008; Parmentier et al. 2017). Sounds are produced in different behavioural contexts, including territorial defence, food competition or predatory attacks (Myrberg et al. 1986; Hawkins and Amorim 2000; Lagardère et al. 2005). Sounds associated with reproductive behaviours have been the most studied types of signals in fish bioacoustics (Amorim 2006). These sounds are generally produced by males to attract potential mates (Parmentier et al. 2010; Longrie et al. 2013), during courtship and to synchronise spawning activities at aggregation sites (Lobel 1992; Rowell et al. 2015; Erisman and Rowell 2017; Jublier et al. 2020), especially the synchronisation of gamete release by conspecifics (Lobel 2002). Using these signals as natural tags, acoustic recordings have been used to locate spawning sites (Lowerre-Barbieri et al. 2008; Walters et al. 2009), define spawning seasons (Luczkovich et al. 2008; Picciulin et al. 2013; Rowell et al. 2015), highlight the presence of cryptic species (Kéver et al. 2016; Picciulin et al. 2019), investigate changes in community richness and diversity (Bertucci et al. 2016; Desiderà et al. 2019), and reveal aspects of the phenology of fish communities (Ruppé et al. 2015; Bertucci et al. 2020) for example.

Although a multitude of coral reef species produce sound, many of these sounds have not yet been described (Fine and Parmentier 2015). The glassy sweeper Pempheris schomburgkii (Müller and Troschel 1848) is a nocturnal coral reef fish living from 3 to $30 \mathrm{~m}$ depth, distributed within the western Atlantic tropical ocean, off Bermuda island and from Florida to southern Brazil (Collette et al. 2015). The distribution of another member of the family Pempheridae, the curved sweeper Pempheris poeyi (Bean 1885), can overlap with that of $P$. schomburgkii. Individuals can reach a maximum size of $15 \mathrm{~cm}$ (Humann and Deloach 2004). They feed on zooplankton as larvae and invertebrates and small fish as adults. Individuals hide in caves and crevices during the day and forage in groups at dusk and during the night before returning at dawn (Gladfelter 1979). Sounds characteristics and some elements of the sonic apparatus have been described in other members of the family Pempheridae present in the Indo-Pacific region, i.e. the New Zealand bigeye Pempheris adspersa (Griffin 1927) in New Zealand (Radford et al. 2015), the silver sweeper Pempheris schwenkii (Bleeker 1855) in Japan (Takayama et al. 2003) and the blackspot sweeper Pempheris oualensis (Cuvier 1831) in Taiwan (Mok et al. 1997; Parmentier et al. 2016). In this family, sounds consist of harmonic pop sounds produced individually or in series with frequencies ranging from 107 to $121 \mathrm{~Hz}$ in $P$. oualensis to $405 \mathrm{~Hz}$ in $P$. adspersa, and all species show up to three harmonic frequencies. Sounds are produced in chorus (i.e. the concurrent acoustic signalling of a large number of individuals) predominantly at night when the calling rate increases. For example, it can increase from around 73 vocalisations per hour during the day to 127 vocalisations per hour at dusk and 117 vocalisations per hour at night in P. adspersa (Radford et al. 2015).

Although there are many differences between species in terms of the swim bladder and its attachments to the vertebral column, muscle origins, and morphology of the recoiling apparatus, the underlying sonic mechanisms are all constructed in a similar way. The rostral part of the swim bladder is connected to a pair of large sonic muscles originating in the head whereas the caudal part is fused with ventral bony expansions of vertebral bodies. Two bladder regions are separated by a stretchable fenestra that allows forward extension of the anterior bladder during fast contraction of sonic muscles, i.e. 100-250 Hz. The mechanism is reset by a recoiling apparatus that runs between the inner face of the anterior swim bladder and a vertebral body expansion. The elasticity of this recoiling apparatus allows the swim bladder to return quickly to its initial position during sonic muscle relaxation (Parmentier et al. 2016).

Contrary to the Indo-Pacific species, little is known about the vocal behaviour and sound production mechanism of the Caribbean species. Using passive acoustics in the wild and captive acoustic recordings, the present study aims to investigate sound production in $P$. schomburgkii, primarily to describe the acoustic characteristics of the signals produced by this species and its phenology. In addition, a morphological study was performed to describe the anatomy of the sound production mechanism. The results of the present study will contribute to the description of acoustic diversity in the Caribbean reefs and also illustrate that passive acoustics can be used to monitor fish populations.

\section{Materials and methods}

\section{Acoustic recordings}

Four individuals (95-127 mm Total Length) were captured using large landing nets $(40 \times 40 \times 40 \mathrm{~cm})$ during snorkelling sessions performed in May 2019 during the day in the "Grand Cul-de-Sac Marin" in the North of the Guadeloupe archipelago $\left(16^{\circ} 21^{\prime} \mathrm{N} ; 61^{\circ} 34^{\prime} \mathrm{W}\right)$ at a depth of $5-10 \mathrm{~m}$. The gender of individuals is unknown. They were placed in a cooler filled with sea water at $28{ }^{\circ} \mathrm{C}$ for approximately $10 \mathrm{~min}$ before being recorded individually. Fish were gently hand-held and maintained within a submerged landing net in the centre of which a hydrophone HTI-96-Min (sensitivity: $-163.9 \mathrm{~dB}$ re $1 \mathrm{~V} \mu \mathrm{Pa}^{-1}$; flat frequency response range $2 \mathrm{~Hz}-30 \mathrm{kHz}$; High Tech, Inc. Long Beach, MS, USA) was placed and connected to a TASCAM DR-05 portable audio recorder (sampling frequency: $44 \mathrm{kHz}, 16$-bit resolution; TEAC, Wiesbaden, Germany). These recordings were made at sea (within $1.2 \mathrm{~m}$ depth) to avoid any issues with 
sound deformation that can occur due to reverberation in an aquarium setting (Akamatsu et al. 2002; Parmentier et al. 2014). Fish were positioned at about $3 \mathrm{~cm}$ from the hydrophone until sounds were obtained. This methodology aimed to elicit the type of sounds produced by the fish when captured by a predator or during distressing events (Parmentier et al. 2011a, 2011b). Recordings were conducted for a maximum of 3 min and were ceased when a sufficient number of sounds were recorded.

Passive acoustic recordings were performed in the area where individuals were captured (Site 1), and in a coral patch close to the slope of Cochon islet in the southern part of the island $\left(16^{\circ} 12^{\prime} \mathrm{N} ; 61^{\circ} 32^{\prime} \mathrm{W}\right.$; Site 2$)$. Recordings were made with an autonomous SNAP acoustic recorder (Loggerhead Instruments, Sarasota, FL, USA) connected to a HTI-

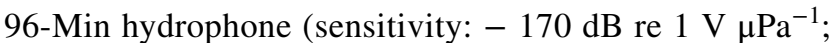
flat frequency response range: $2 \mathrm{~Hz}-30 \mathrm{kHz}$; High Tech Inc, Long Beach, MS, USA) positioned on the bottom at a depth of $10 \mathrm{~m}$ by professional divers of the Marine Biology laboratory at the University of the French West Indies. The system was programmed to record for $1 \mathrm{~min}$ every $10 \mathrm{~min}$ (sampling frequency of $44 \mathrm{kHz}, 16$-bit resolution). On site 1 , recordings were made from July 8 to 10,2019 . On site 2 , three recording sessions were made, the first one from May 6 to 9, 2019, another from November 20 to 22, 2019 and finally from January 15 to 17, 2020.

\section{Acoustic data processing}

All recordings were digitised at $44.1 \mathrm{kHz}$ (16-bit resolution) and analysed with Avisoft SASLab Pro version 5.2.13 software (Avisoft Bioacoustics, Glienicke, Germany). The sounds analysed included all those collected when individuals were hand-held as well as 20 sounds from passive acoustic recordings with a good signal-to-noise ratio (identified as originating from $P$. schomburgkii based on aural features characterised during the analysis of hand-held sounds). A band-pass filter between $50 \mathrm{~Hz}$ and $2 \mathrm{kHz}$ was applied (Lobel et al. 2010; Tavolga et al. 2012). Sounds were produced in series and the following acoustic features were measured: the series duration (from the beginning of the first sound to the end of the last sound), the number of sounds in a series, the sound duration, the sound period (from the start of a sound to the start of the subsequent one), the dominant frequency and harmonics of the sound, the number of pulses detected within a sound and the pulse period (peakto-peak interval between two consecutive pulses in a sound) (Fig. 1). Temporal features were measured from oscillograms whereas frequencies were obtained from logarithmic power spectra (Fast Fourier Transform FFT, 128 points, Hamming window, 75\% overlap). Passive acoustic recordings were aurally and visually inspected to detect sounds of P. schomburgkii. Each detected sound was tagged using the "insert label" function of Avisoft software.

\section{Morphology}

After individual recordings, all four specimens were euthanized with an overdose of tricaine methanesulfonate (MS222) and fixed in $7 \%$ formalin for approximately 2 weeks before transferring into $70 \%$ ethanol. Three fish specimens were dissected and examined with a Wild M10 (Leica) binocular microscope equipped with a camera lucida to study the swim bladder anatomy and muscle organisation. One of
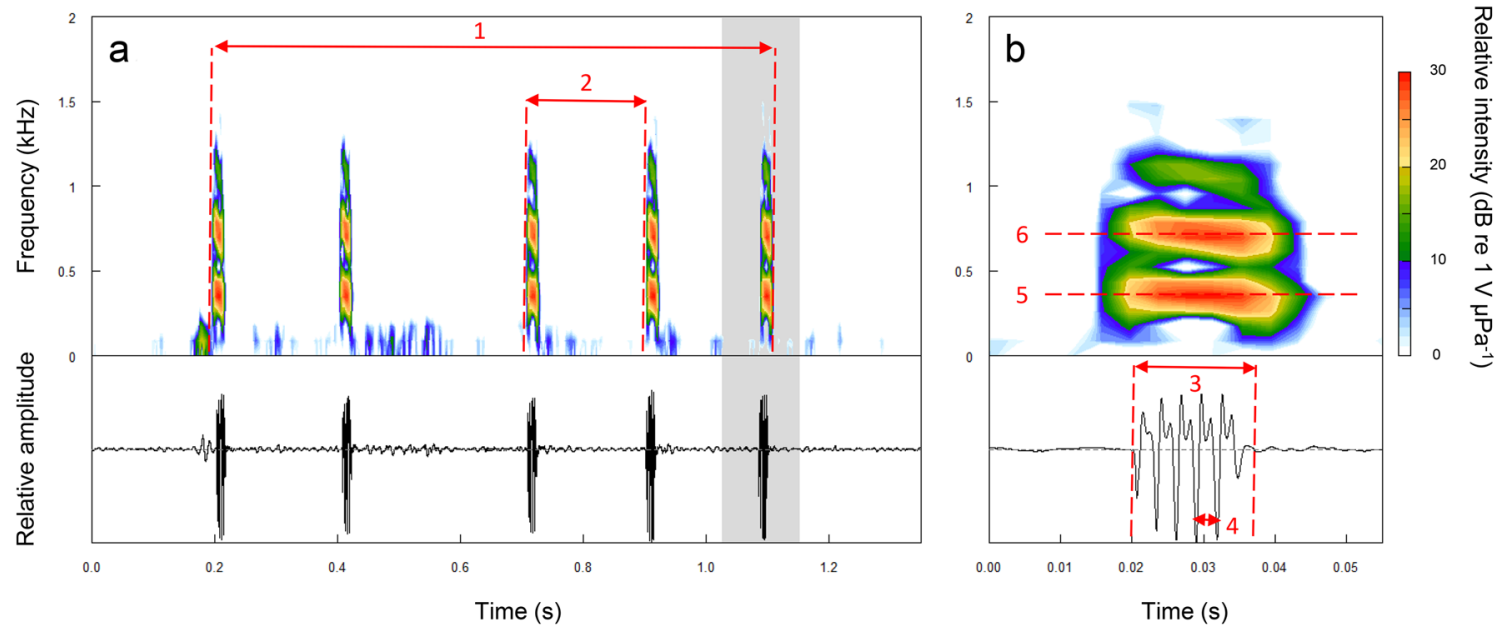

Fig. 1 Spectrograms (top) and oscillograms (bottom) of a series of five sounds (a) and of the last sound of the series (b) produced by the glassy sweeper Pempheris schomburgkii (made with R-studio using the Seewave package). Measured variables represented: duration of the series (1), period of sounds (2), sound duration (3), pulse period (4), fundamental frequency (5) and first harmonic (6). Grey area in (a) indicates the sound illustrated in (b) 
these specimens was then used to study the fish skeleton at the level of the sound-producing apparatus. Scanning was completed using a RX EasyTom (RX Solutions, Chavanod, France; http://www.rxsolutions.fr), with an aluminium filter. Images were generated at a voltage of $90 \mathrm{kV}$ and a current of $333 \mu \mathrm{A}$, with a set frame rate of 12.5 and 5 average frames per image. This generated 2370 images and a voxel size of $34.9 \mu \mathrm{m}$. Reconstruction was performed using X-Act software from RX Solutions. Segmentation, visualisation, and analysis were performed using Dragonfly software (Object Research Systems (ORS) Inc, Montreal, Canada, 2019; software available at http://www.theobjects.com/dragonfly). Three-dimensional (3D) images were produced in 16-bit and subsequently converted into 8-bit voxels using ImageJ (Abràmoff et al. 2014). Three-dimensional processing and rendering, performed according to the protocols described by Zanette et al. (2014), were obtained after semi-automatic segmentation of the body, brain and inner ear using a 'generated surface'. Direct volume renderings (iso-surface reconstructions) were used to visualise a subset of selected voxels of body, brain and inner ear in AMIRA 2019.2.

The last specimen was deposited at the Royal Belgian Institute of Natural Science and received the catalogue number IRSNB 25679.

\section{Statistical analysis}

The number of sounds identified from passive acoustic recordings were grouped in 8 periods of $3 \mathrm{~h}$ starting from $1200 \mathrm{~h}$ (period 1: 1200-1450 h, period 2: 1500-1750 h, $\ldots$, period 8: $0900 \mathrm{~h}-1150 \mathrm{~h})$. The normality of the data was checked by Shapiro-Wilk tests $(\mathrm{W}=0.344-0.754$, all $p<10^{-3}$ ) and non-parametric Kruskal-Wallis tests were performed to compare the number of sounds detected between the 3-h periods for each recording session. Post hoc Dunn's multiple pairwise comparisons tests were subsequently used to identify significant differences. All statistical analysis were performed with R-studio (1.0.143) with a significance threshold of $\alpha=0.05$.

\section{Results}

\section{Acoustic activity}

Sounds recorded in captivity were produced in series of $6 \pm 5$ sounds (mean $\pm S D$; min $-\max =2-26$ ) which lasted $1060 \pm 1120 \mathrm{~ms}(72-4940 \mathrm{~ms})$ with a sound period of $197 \pm 136 \mathrm{~ms}(38-1094 \mathrm{~ms})$. Sounds lasted $16 \pm 2 \mathrm{~ms}$ (10-23 ms), consisted of $5 \pm 1$ pulses (3-8) with a period of $3 \pm 1 \mathrm{~ms}(3-4)(\mathrm{N}=237$ sounds from 38 series) (Online Resource 1). The sound's fundamental frequency (H0) was $359 \pm 11 \mathrm{~Hz}$ (344-409) (Fig. 1). Up to 4 harmonics could be identified in the recordings. The first harmonic (H1) was $720 \pm 22 \mathrm{~Hz}(689-795)$ and the second harmonic $(\mathrm{H} 2)=1074 \pm 27 \mathrm{~Hz}$. The last two harmonics were often weak or absent and could not be measured for all sounds (Table 1, Fig. 1).

Sounds recorded in May 2019 at Site 2 were significantly longer, 39 $\pm 7 \mathrm{~ms}$ (29-52 ms), than sounds recorded in captivity (Kruskal-Wallis, $\chi_{4}^{2}=148.98, p<10-3$ ) with significantly more pulses, $13 \pm 2$ pulses (9-17) (Kruskal-Wallis, $\left.\chi_{4}^{2}=123.46, p<10-3\right)$. No significant differences were found in the pulse period (Kruskal-Wallis, $\chi_{4}^{2}=2.774$, $p=0.428$ ), fundamental frequency (Kruskal-Wallis, $\chi_{4}^{2}=2.024, p=0.57$ ) or first harmonic (Kruskal-Wallis, $\chi_{4}^{2}=2.774, p=0.428$ ) of the sounds (Table 1).

Recordings made at Site 1 (July 8-10 2019, where the individuals were captured) over $48 \mathrm{~h}$ revealed a drastic increase in the number of sounds at dusk (1800 h) with a maximum average number of 42 sounds $\min ^{-1}$ detected. The chorusing nature of this activity prevented clear detection of series and sounds could only be detected as single units. This sustained acoustic activity then gradually decreased until $0000 \mathrm{~h}$. Very few sounds could be detected until $1 \mathrm{~h}$ before dawn $(0500 \mathrm{~h})$. The latter period of sonic activity was less intense with 21 sounds. $\mathrm{min}^{-1}$ and shorter, ending at $0600 \mathrm{~h}$. During day, only a few sounds could occasionally be detected, never exceeding 4 sounds $\min ^{-1}$ (Fig. 2).

The same pattern was observed at Site 2 for the recordings performed in May and November 2019 and in January 2020 (Fig. 3). The duration of the dusk chorus, however, was shorter, occurring mostly between 1800 and $2100 \mathrm{~h}$, and the dawn activity scarcely detectable. Up to 492 sounds $\mathrm{min}^{-1}$

Table 1 Acoustic characteristics of the sounds attributed to Pempheris schomburgkii

\begin{tabular}{|c|c|c|c|c|c|}
\hline Total duration (ms) & Number of pulses & Pulse period (ms) & $\begin{array}{l}\text { Fundamental frequency } \\
(\mathrm{Hz})\end{array}$ & $\begin{array}{l}\text { First } \\
\text { harmonic }(\mathrm{Hz})\end{array}$ & $\begin{array}{l}\text { Second } \\
\text { harmonic }(\mathrm{Hz})\end{array}$ \\
\hline $\begin{array}{cc}\text { Captivity } & 16.03 \pm 2.46 \\
N=236 & (10.4-22.9)\end{array}$ & $\begin{array}{l}5.04 \pm 0.83 \\
(3-8)\end{array}$ & $\begin{array}{l}2.84 \pm 0.18 \\
(2.3-4.1)\end{array}$ & $358.67 \pm 7.83(344-409)$ & $720.56 \pm 21.76(689-795)$ & $\begin{array}{l}1074.56 \pm 26.35 \\
(1017-1157)\end{array}$ \\
\hline $\begin{array}{c}\text { May } 201939.15 \pm 6.31 \\
N=20\end{array}$ & $\begin{array}{l}12.85 \pm 2.06 \\
(9-17)\end{array}$ & $\begin{array}{l}2.74 \pm 0.62 \\
(1-5.7)\end{array}$ & $344.26 \pm 10.76(323-356)$ & $\begin{array}{l}696.89 \pm 23.02 \\
(667-728)\end{array}$ & $\begin{array}{l}1036.5 \pm 33.23 \\
(1013-1060)\end{array}$ \\
\hline
\end{tabular}


Fig. 2 Average number of sounds attributed to Pempheris schomburgkii, as detected every 10 min on a $24 \mathrm{~h}$ basis on Site 1, from July 8, 2019 to July 10 , 2019. Grey area represents night time

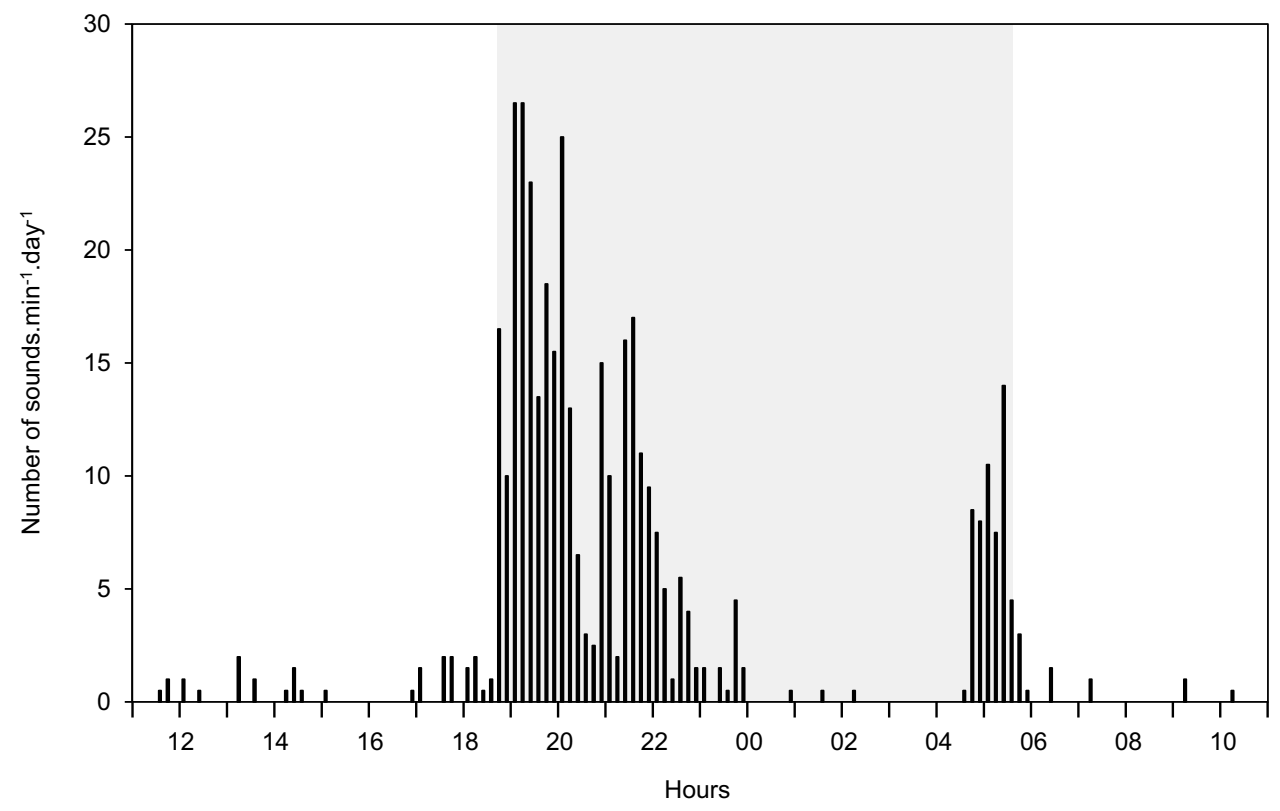

and 426 sounds $\min ^{-1}$ were detected, respectively, in May 2019 and January 2020. The vocal activity detected between 1800 and $2100 \mathrm{~h}$ was significantly decreased in November 2019 (Kruskal-Wallis, $\chi_{2}^{2}=10.55, p=0.0051$ ) with only 180 sounds. $\min ^{-1}$ detected.

\section{Morphology}

P. schomburgkii has a two-chambered swim bladder connected by a short duct, and the anterior chamber is shorter than the posterior one (Fig. 4). The anterior chamber of the swim bladder extends from the 1 st to the 8 th vertebra, and the posterior chamber to the 9th-11th vertebra (Fig. 4). This second chamber is kidney shaped, its posterior part lying against the first haemal spine. The anterior chamber possesses two bands of fibrous connective tissue (originating from the tunica externa) that extends from the dorsal surface of the swim bladder to the 3rd vertebral centra, just beyond the insertion of the 3 rd epineural. This pair of bands is also the posterior margin of a narrow slit that corresponds to the swim bladder fenestra and runs perpendicular to the swim bladder from the right to the left band. In front of the slit, the anterior part of the first chamber can undergo anteroposterior movement. The posterior part is firmly attached to the margins of the ventral bony expansions of the central vertebrae (4th, 5th and 6th vertebrae). Moreover, a sheet of elastic connective tissue extends from the bony expansion of the 4th vertebrae and inserts on the posterior margin of the anterior part of the swim bladder. A pair of large sonic muscles originates on the postero-lateral part of the skull (on the prootic) and inserts dorsally on the movable anterior part of the first chamber, between the swim bladder bands. Contractions of these muscles pull the anterior part of the swim bladder rostrally but the inner sheet of connective tissue should function as a recoiling system that antagonises the action of the sonic muscles. Indeed, the elastic nature of the recoiling apparatus supports its role in helping the swim bladder to recover its initial position during relaxation of the sonic muscles.

\section{Discussion}

Passive acoustic surveys and recordings performed in captivity were employed to characterise the sound produced by the glassy sweeper $P$. schomburgkii together with its phenology. Sounds consisted of a series of harmonic pops with a dominant frequency of approximately $360 \mathrm{~Hz}$. They were produced in chorus, commencing after sunset and lasting up to $3 \mathrm{~h}$. A few sounds could also be detected before sunrise. In addition, an anatomical study permitted the description of the specialised morphology of the swim bladder and the associated structures that could be involved in the sound production mechanism of the family Pempheridae.

The discrepancy between sounds recorded on the reef and captive animals suggest that there are different types of sounds with different biological functions. This is supported by the significantly longer sounds with more pulses recorded at sea than when individuals were handheld. Short sounds (with few pulses) would be intended for heterospecifics whereas longer sounds (with more pulses) would be addressed to conspecifics. Similar results were found in the yellowtail damselfish Dascyllus flavicaudus (Randall and Allen 1977) (Parmentier et al. 2010) and in the Hawaiian dascyllus Dascyllus albisella (Gill 1862) (Mann and Lobel 1998). The shortest sounds were 
Fig. 3 Average number of sounds attributed to Pempheris schomburgkii, as detected every $10 \mathrm{~min}$ on a $24 \mathrm{~h}$ basis on Site

2. a From May 6, 2019 to May 9, 2019, b from November 20, 2019 to November 22, 2019 and $\mathbf{c}$ from January 15, 2020 to January 17,2020 . Note the difference in the $y$-axis between $\mathbf{a}-\mathbf{c}$ and $\mathbf{b}$. Grey areas represent night time a

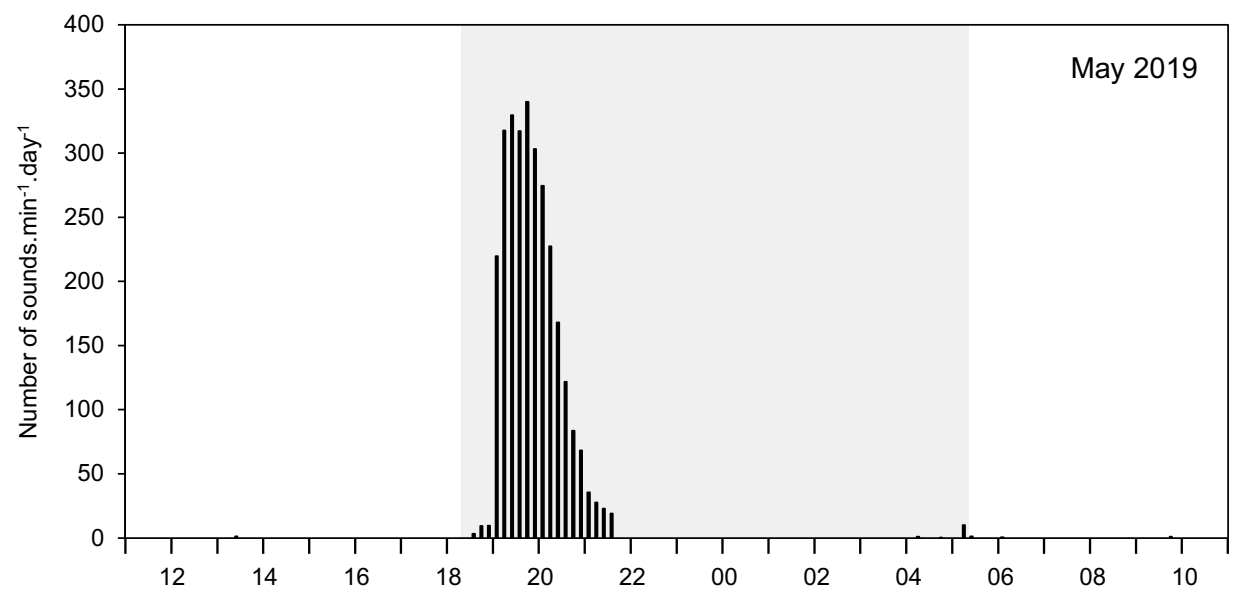

b

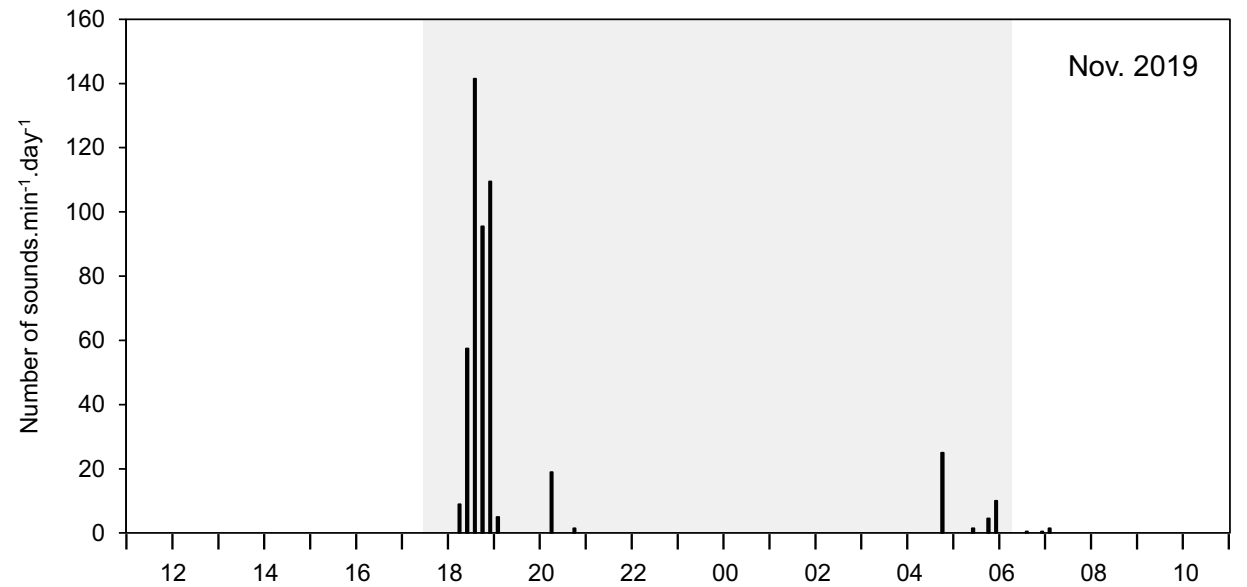

C

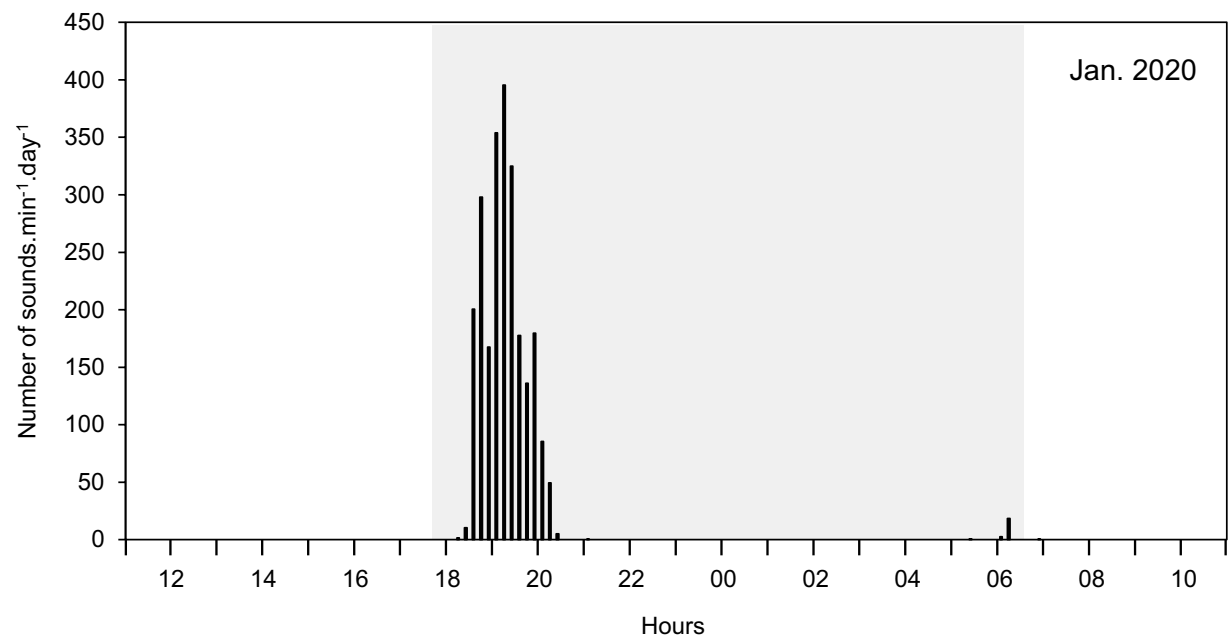

produced by males during encounters with heterospecifics or fights with conspecifics, while longer sounds were produced towards conspecifics during courtship displays and signal jumps, a behaviour initiated by males when female(s) entered their territory or in response to signal jumps made by other males.

A clear conclusion on the function of the distress calls produced by hand-held individuals could not be drawn. The signals suggest that stress can motivate sound production, and calls can serve as a warning signal to conspecifics or an aposematic signal for predators (Kaatz 2002; Bosher et al. 2006). In P. schwenkii, sounds were observed during the approach of a school suggesting they may indeed possibly function as a distress call or as an alert signal indicating the threat of heterospecific intruders (Takayama et al. 2003). Furthermore, acoustic signals produced in choruses are also thought to be important for territory defence and mate attraction (Rehberg-Besler et al. 2017). The recordings 
a

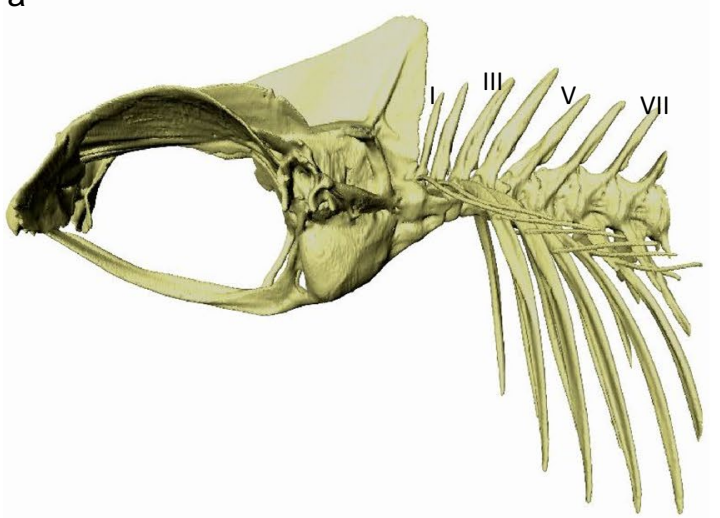

c

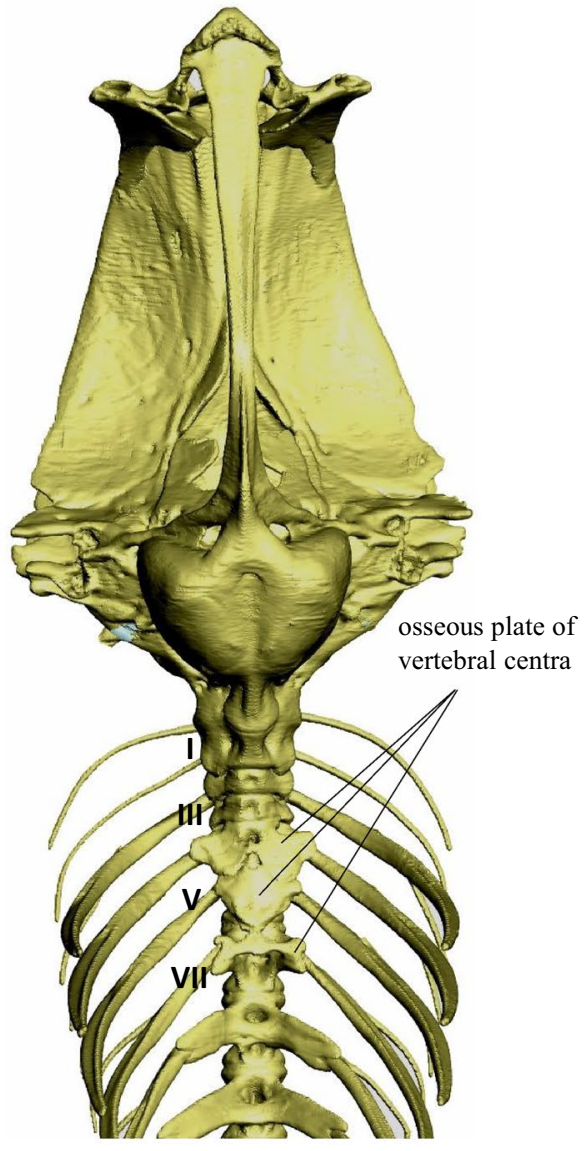

b

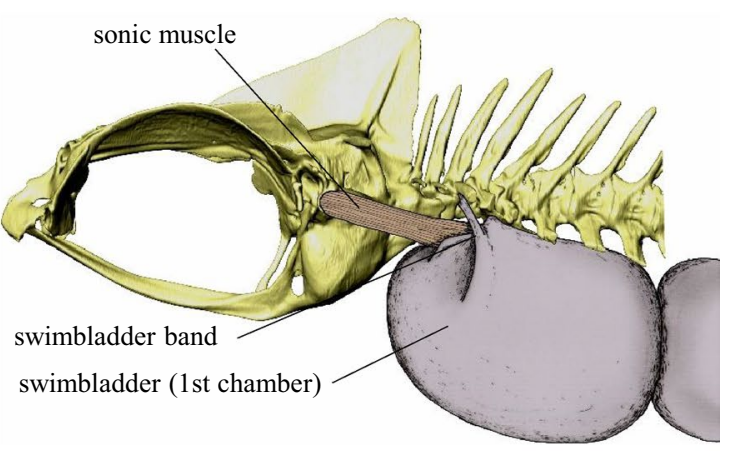

d

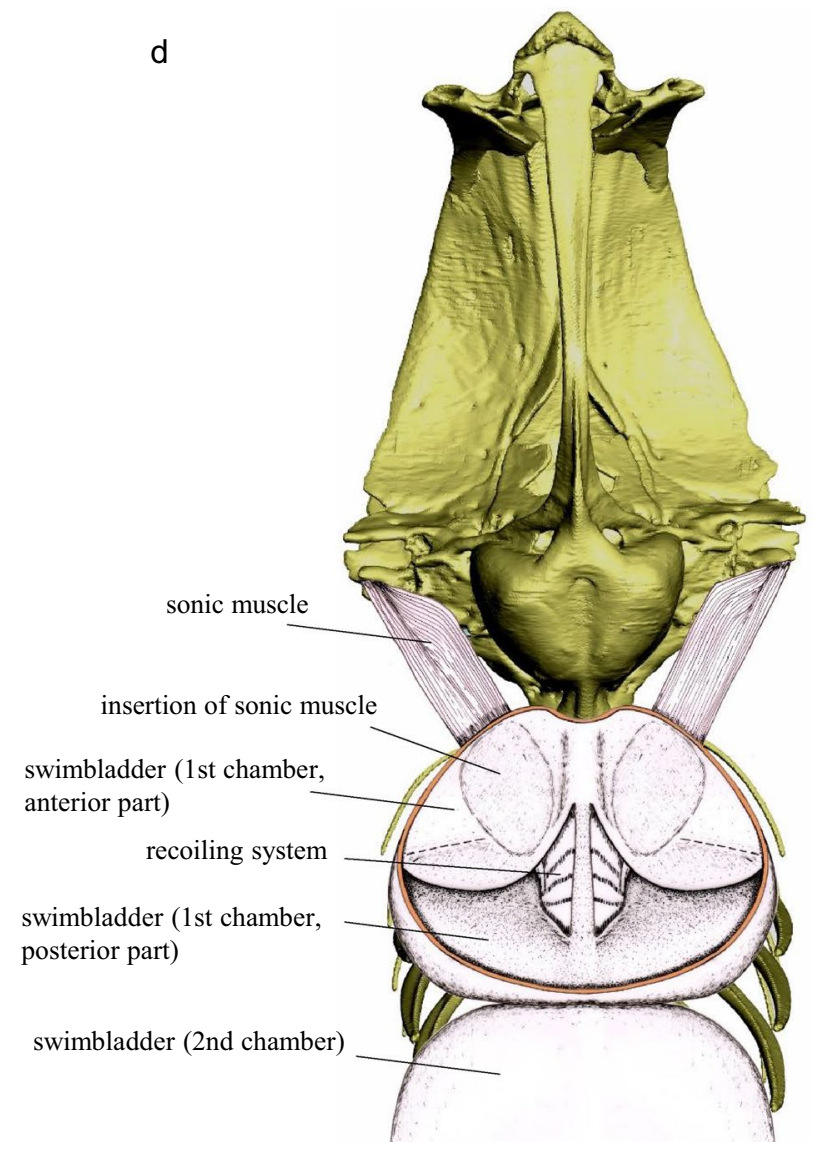

Fig. 4 Left lateral $(\mathbf{a}, \mathbf{b})$ and ventral views $(\mathbf{c}, \mathbf{d})$ of the sound-producing apparatus in Pempheris schomburgkii showing the anterior part of the skeleton, the swim bladder and associated muscles. The ventral view allows for the discrimination of the bony expansions at the level

suggest that sounds produced at sea could perform a different function and may be involved in other social contexts. For example, Pempheridae may use chorusing sounds as contact calls to rapidly locate conspecific aggregations in dark environments. The potential role of sound production in contact calls is supported by both the study of Gladfelter of the vertebra (c). The ventral wall of the swim bladder has been removed for viewing of the inner organisation of the swim bladder and the recoiling system organisation (drawn by E. P)

(1979), indicating that $P$. schomburgkii becomes more active after dusk and before dawn, and by the temporal pattern of sound production, observed in the present study and in other members of the genus. Therefore, the diel pattern of sound production found in the present study would indicate that acoustic signals are particularly important for the 
synchronisation of schooling and other behaviours when individuals leave their shelter at night (Larsson and Abbott 2018). Radford et al. (2015) estimated that the active space of $P$. adspersa signals, ranging from a minimum distance of $0.6 \mathrm{~m}$ to a maximum distance of $31.6 \mathrm{~m}$, allows fish to reliably swim toward their conspecifics and maintain school cohesion. This could potentially be a way to optimise food foraging (Helfman 1986) or as a strategy to reduce predation risk (Krause and Ruxton 2002) which becomes more important when predators such as Serranidae (groupers and hamlets), Lutjanidae (porgies and snappers) and Aulostomidae (trumpetfish) are present (Gladfelter 1979).

In situ recordings also yielded insights into the seasonality of sound production in the species and sounds may be related to reproductive behaviour. The most active periods were recorded in May and January. Recordings performed in November showed a lower number of sounds as well as a shorter chorus. Reproduction occurs in P. schomburgkii in June and from September to October (Pastor Gutiérrez and Báez Hidalgo 2003). The sustained vocal activity observed in May could, therefore, be associated with the imminence of the first reproductive period while the reduced choruses recorded in November could indicate the end of the second one. Thus, acoustic signals could serve the function of facilitating aggregation and attraction of individuals during critical mating periods, as observed in other families, such as Serranidae (Bertucci et al. 2015; Jublier et al. 2020) or Sciaenidae (Connaughton and Taylor 1995; Parmentier et al. 2017).

The level of acoustic activity detected in January was similar to the level detected in May. This may indicate that the reproductive period is longer than previously described for this species or alternatively, it may indicate that sounds are also associated with another social activity. In either case, this result further emphasises that passive acoustics can identify previously unknown sounds produced by fish species and can also help to understand the phenology of its biological activities (Jublier et al. 2020). These findings call for additional long-term passive acoustic monitoring and visual observations to learn more about the social role of vocal communication in the glassy sweeper. Future studies may reveal that the second Caribbean species, the curved sweeper $P$. poeyi, also produces sound in the same areas with potential species-specific features. Sounds of $P$. poeyi may then possibly be present in the passive recordings performed in the present study, further illustrating the need to describe acoustic diversity across different species of fish.

Aside from the previously mentioned temporal features, sounds presented no differences in their pulse period and spectral composition, strongly suggesting that they were produced by the same mechanism. A similar mechanism is currently known only in Glaucosomatidae and Pempheridae (Parmentier et al. 2016). The dominant frequency of the sounds resulting from this mechanism and the presence of multiple harmonics indicate that the sounds are most probably elicited by superfast muscles, as already suggested for Terapon jarbua, Pempheris oualensis and Pelates quadrilineatus (Parmentier et al. 2016). Therefore, despite other species-specific variations in acoustic features, the shared acoustic features support a common sonic mechanism across these species, which suggests that the sound production mechanism is a synapomorphy within Pempheriforms (Betancur-R et al. 2013). It is worth noting that certain acoustic characteristics, particularly the dominant frequency, can provide information on the individual producing the sound for some species, such as its size, sex or age (Lobel and Mann 1995; Colleye et al. 2009). In species producing sounds with fast contracting muscles, the relationship between the dominant frequency and the fish size is weak, as further supported by the low variability in frequencies recorded in this study (Parmentier and Fine 2016). Thus, it may not be possible to resolve information on individuals using passive acoustic recordings from this species, however, recordings may still confirm the potential group-level functions of sound production in Pempheridae.

In conclusion, passive acoustic recordings made during this study have permitted the description of the sounds produced by a common Caribbean fish and have also offered insights into the pattern of calling at different times of the day and year. While further studies are required to complement the present results, this study contributes to continuing efforts to describe the diversity of sound production in fishes, the role it may play in their ecologies. Furthermore, the recoiling apparatus described in this study further highlights the diversity of sound production mechanisms found in teleost fishes. These data may be of particular interest to surveys of ichthyological diversity based on sound recordings. Since biotic sounds are the first to change in response to environmental degradation (Sueur and Farina 2015), their monitoring appears to be a good proxy for environmental change, allowing fluctuations to be identified as early as possible, thereby permitting rapid action to reduce their impact (Risch and Parks 2017).

Supplementary Information The online version of this article (https:// doi.org/10.1007/s00227-021-03829-8) contains supplementary material, which is available to authorized users.

Acknowledgements The authors would like to thank Dr. Lily Fogg for her assistance in English editing and proofreading of the final version of our manuscript. We also thank two anonymous reviewers for their comments.

Author contributions FB, EP, DL and MR-T designed the study. FB, $\mathrm{EP}, \mathrm{SC}$ and DL collected the data. FB, EP and AH analysed the data. FB wrote the manuscript. All the authors contributed to substantial revisions. 
Funding This work was supported by several grants: Fondation de France (2019-08602), LabEx CORAIL (project 2018 Emul), ANR-19-CE34-0006-Manini.

Availability of data and material Data will be made fully available upon reasonable request to $\mathrm{FB}$.

\section{Compliance with ethical standards}

Conflict of interest The authors declare no conflicts of interest and no competing interests.

Ethical approval The research required no permits and morphology investigations followed rules approved by the ethical commission of the University of Liège.

Consent for publication All listed authors agreed on the publication of the present research and accepted responsibility for the work presented here.

\section{References}

Abràmoff MD, Magalhães PJ, Ram SJ (2004) Image processing with Image. J Biophoton Int 11:36-42

Akamatsu T, Okumura T, Novarini N, Yan HY (2002) Empirical refinements applicable to the recording of fish sounds in small tanks. $\mathrm{J}$ Acoust Soc Am 112:3073-3082

Amorim MCP (2006) Diversity in sound production in fish. In: Ladich F, Collin SP, Moller P, Kapoor BG (eds) Communication in fishes. Science Publishers Inc., Enfield, pp 71-105

Bass AH, Ladich F (2008) Vocal-acoustic communication: from behavior to neurons. In: Popper AN, Fay RR, Webb JF (eds) Fish Bioacoustics. Springer, New York, pp 253-278

Bertucci F, Maratrat K, Berthe C, Besson M, Guerra AS, Raick X, Lerouvreur F, Lecchini D, Parmentier E (2020) Local sonic activity reveals potential partitioning in a coral reef fish community. Oecologia 193:125-134

Bertucci F, Parmentier E, Lecellier G, Hawkins AD, Lecchini D (2016) Acoustic indices provide information on the status of coral reefs: an example from Moorea Island in the South Pacific. Sci Rep 6:33326

Bertucci F, Lejeune P, Payrot J, Parmentier E (2015) Sound production by dusky grouper Epinephelus marginatus at spawning aggregation sites. J Fish Biol 87:400-421

Betancur RR, Broughton RE, Wiley EO, Carpenter K, López JA, Li C, et al. (2013) The Tree of Life and a New Classification of Bony Fishes. Edition 1. PLOS Currents Tree of Life Apr 18

Bosher B, Newton S, Fine M (2006) The spine of the channel catfish, Ictalurus punctatus, as an anti-predator adaptation: An experimental study. Ethology 112:188-195

Collette B, Dooley J, Aiken KA, Marechal J, Pina Amargos F, SinghRenton KR (2015) Pempheris schomburgkii. The IUCN Red List of Threatened Species 2015:e.T16749725A16750102

Colleye O, Frederich B, Vandewalle P, Casadevall M, Parmentier E (2009) Agonistic sounds in the skunk clownfish Amphiprion akallopisos: size-related variation in acoustic features. J Fish Biol 75:908-916

Connaughton MA, Taylor MH (1995) Seasonal and daily cycles in sound production associated with spawning in the weakfish, Cynoscion regalis. Environ Biol Fish 42:233-240

Desiderà E, Guidetti P, Panzalis P, Navone A, Valentini-Poirrier CA Boissery P, Gervaise C (2019) Acoustic fish communities: sound diversity of rocky habitats reflects fish species diversity. Mar Ecol Prog Ser 608:183-197

Erisman BE, Rowell TJ (2017) A sound worth saving: acoustic characteristics of a massive fish spawning aggregation. Biol Lett 13:20170656

Fine ML, Parmentier E (2015) Mechanisms of fish sound production. In: Ladich F (ed) Sound Communication in Fishes. Springer, New York, pp 77-126

Gannon DP (2008) Passive acoustic techniques in fisheries science: a review and prospectus. Trans Am Fish Soc 137:638-656

Gladfelter WB (1979) Twilight migrations and foraging activities of the copper sweeper Pempheris schomburgkii (Teleostei: Pempheridae). Mar Biol 50:109-119

Hawkins AD, Amorim MCP (2000) Spawning sounds of the male haddock, Melanogrammus aeglefinus. Environ Biol Fish 59:29-41

Helfman GS (1986) Fish behaviour by day, night and twilight. In: Pitcher TJ (ed) The behaviour of teleost fishes. Springer, Boston, pp 366-387

Humann P, Deloach N (2004) Poissons Coralliens, identification, floride caraibes bahamas, 2e edn. PLB Editions, Guadeloupe

Jublier N, Bertucci F, Kéver L, Colleye O, Ballesta L, Nemeth RS, Lecchini D, Rhodes KL, Parmentier E (2020) Passive monitoring of phenological acoustic patterns reveals the sound of the camouflage grouper, Epinephelus polyphekadion. Aquat Cons Mar Fresh Ecosys 30:42-52

Kaatz IM (2002) Multiple sound-producing mechanisms in teleost fishes and hypotheses regarding their behavioral significance. Bioacoustics 12:230-233

Kéver L, Lejeune P, Michel LN, Parmentier E (2016) Passive acoustic recording of Ophidion rochei calling activity in Calvi Bay (France). Mar Ecol 37:1315-1324

Krause J, Ruxton GD (2002) Living in Groups. Editions Broché, Oxford

Ladich F, Fine ML (2006) Sound-generating mechanisms in fishes: a unique diversity in vertebrates. In: Ladich F, Collin SP, Moller P, Kapoor BG (eds) Communication in fishes. Science Publishers, Enfield, pp 3-34

Lagardère JP, Millot S, Parmentier E (2005) Aspects of sound communication in the pearlfish Carapus boraborensis and Carapus homei (Carapidae). J Exp Zool A 303:1066-1074

Larsson M, Abbott BW (2018) Is the capacity for vocal learning in vertebrates rooted in fish schooling behavior? Evol Biol 45:359-373

Lobel PS, Kaatz IM, Rice AN (2010) Acoustical behavior of coral reef fishes. In: Cole KS (ed) Reproduction and sexuality in marine fishes: patterns and processes. University of California Press, Berkeley, pp 307-386

Lobel PS, Mann DA (1995) Spawning sounds of the damselfish, Dascyllus albisella (Pomacentridae), and relationship to male size. Bioacoustics 6:187-198

Lobel PS (2002) Diversity of fish spawning sounds and the application of passive acoustic monitoring. Bioacoustics 12:286-289

Lobel P (1992) Sounds produced by spawning fishes. Environ Biol Fish 33:351-358

Longrie N, Poncin P, Denoël M, Gennotte V, Delcourt J, Parmentier E (2013) Behaviours associated with acoustic communication in Nile tilapia (Oreochromis niloticus). PLoS ONE 8:e61467

Lowerre-Barbieri SK, Barbieri LR, Flanders JR, Woodward AG, Cotton CF, Knowlton MK (2008) Use of passive acoustics to determine red drum spawning in Georgia waters. Trans Am Fish Soc 137:562-575

Mann DA, Lobel PS (1998) Acoustic behavior of the damselfish Dascyllus albisella: behavioral and geographic variation. Environ Biol Fish 51:421-428

Mok HK, Yeh MW, Kuo SC (1997) Sound characteristics and diurnal vocal activity of sweepers, Pempheris oualensis (Pempheridae, Perciformes). Proc Natl Sci Coun Repub China B 21:175-179 
Myrberg AAJ, Mohler M, Catala J (1986) Sound production by males of a coral reef fish (Pomacentrus partitus): its significance to females. Anim Behav 34:913-923

Parmentier E, Di Iorio L, Picciulin M, Malavasi S, Lagardère JP, Bertucci F (2017) Consistency of spatiotemporal sound features supports the use of passive acoustics for long-term monitoring. Anim Cons 21:211-220

Parmentier E, Fine ML (2016) Fish sound production: insights. In: Suthers R, Tecumseh F, Popper AN, Fay RR (eds) Vertebrate sound production and acoustic communication. Springer, New York, pp 19-49

Parmentier E, Fine ML, Mok HK (2016) Sound production by a recoiling system in the Pempheridae and Terapontidae. J Morphol 277:717-724

Parmentier E, Tock J, Falguière JC, Beauchaud M (2014) Sound production in Sciaenops ocellatus: Preliminary study for the development of acoustic cues in aquaculture. Aquaculture 432:204-211

Parmentier E, Vandewalle P, Brié C, Dinraths L, Lecchini D (2011a) Comparative study on sound production in different Holocentridae species. Front Zool 8:12

Parmentier E, Boyle KS, Berten L, Brié C, Lecchini D (2011b) Sound production and mechanism in Heniochus chrysostomus (Chaetodontidae). J Exp Biol 214:2702-2708

Parmentier E, Kéver L, Casadevall M, Lecchini D (2010) Diversity and complexity in the acoustic behaviour of Dacyllus flavicaudus (Pomacentridae). Mar Biol 157:2317-2327

Pastor Gutiérrez L, Báez Hidalgo M (2003) Características biológicas de la Catalufa cobriza, Pempheris schomburgkii (Pisces: Pempheridae) en la Costa Norte de La Habana, Cuba. Rev Invest Mar 24:127-131

Picciulin M, Kéver L, Parmentier E, Bolgan M (2019) Listening to the unseen: passive acoustic monitoring reveals the presence of a cryptic fish species. Aquat Cons Mar Fresh Ecosys 29:202-210

Picciulin M, Bolgan M, Codarin A, Fiorin R, Zucchetta M, Malavasi S (2013) Passive acoustic monitoring of Sciaena umbra on rocky habitats in the Venetian littoral zone. Fish Res 145:76-81

Picciulin M, Sebastianutto L, Codarin A, Calcagno G, Ferrero EA (2012) Brown meagre vocalization rate increases during repetitive boat noise exposures: a possible case of vocal compensation. J Acoust Soc Am 132:3118-3124

Radford CA, Ghazali S, Jeffs AG, Montgomery JC (2015) Vocalisations of the bigeye Pempheris adspersa: characteristics, source level and active space. J Exp Biol 218:940-948

Rehberg-Besler N, Doucet SM, Mennill DJ (2017) Overlapping vocalizations produce far-reaching choruses: a test of the signal enhancement hypothesis. Behav Ecol 28:494-499
Risch D, Parks SE (2017) Biodiversity assessment and environmental monitoring in freshwater and marine biomes using ecoacoustics. In: Farina A, Gage SH (eds) Ecoacoustics. The ecological role of sounds, Wiley, Oxford, pp 145-168

Rountree RA, Gilmore RG, Goudey CA, Hawkins AD, Luczkovich JJ, Mann DA (2006) Listening to fish. Fisheries 31:433-446

Rowell T, Nemeth R, Schärer M, Appeldoorn R (2015) Fish sound production and acoustic telemetry reveal behaviors and spatial patterns associated with spawning aggregations of two Caribbean groupers. Mar Ecol Prog Ser 518:239-254

Ruppé L, Clément G, Herrel A, Ballesta L, Décamps T, Kéver L, Parmentier E (2015) Environmental constraints drive the partitioning of the soundscape in fishes. Proc Nat Acad Sci 112:6092-6097

Slabbekoorn H, Bouton N, van Opzeeland I, Coers A, ten Cate C, Popper AN (2010) A noisy spring: the impact of globally rising underwater sound levels on fish. Trends Ecol Evol 25:419-427

Sueur J, Farina A (2015) Ecoacoustics: the ecological investigation and interpretation of environmental sound. Biosemiotics 8:493-502

Takayama M, Onuki A, Yosino T, Yoshimoto M, Ito H, Kohbara J, Somiya H (2003) Sound characteristics and the sound producing system in silver sweeper, Pempheris schwenkii (Perciformes: Pempheridae). J Mar Biol Assoc Unit King 83:1317-1320

Tavolga WN, Popper AN, Fay RR (2012) Hearing and Sound Communication in Fishes. Springer, New York

Vasconcelos RO, Amorim MCP, Ladich F (2007) Effects of ship noise on the detectability of communication signals in the Lusitanian toadfish. J Exp Biol 210:2104-2112

Walters S, Lowerre-Barbieri S, Bickford J, Mann D (2009) Using a passive acoustic survey to identify spotted seatrout spawning sites and associated habitat in Tampa Bay, Florida. Trans Am Fish Soc 138:88-98

Zanette I, Zhou T, Burvall A, Lundström U, Larsson DH, Zdora M, Thibault P, Pfeiffer F, Hertz HM (2014) Speckle-based x-ray phase-contrast and dark-field imaging with a laboratory source. Phys Rev Lett 112:253903

Publisher's Note Springer Nature remains neutral with regard to jurisdictional claims in published maps and institutional affiliations. 